A comparative study between the relative weight and the weight for the methods of the sum of the weights and the product of the weights in the AHP method in the selection of the best material for the adsorption of dyes from wastewater

\title{
Um estudo comparativo entre o peso relativo e o peso para os métodos da soma dos pesos e o produto dos pesos no método AHP na seleção do melhor material para a adsorção de corantes de águas residuárias
}

Article Info:

Article history: Received 2021-03-29 / Accepted 2021-05-21 / Available online 2021-05-21

doi: $10.18540 /$ jcecvl7iss2pp12265-01-13e

\author{
Josemar Pereira da Silva \\ ORCID: https://orcid.org/0000-0001-8714-5744 \\ Federal Institute of Goias, Brazil \\ E-mail: josemarsilva.eq@gamil.com \\ Kely Lopes Caiado \\ ORCID: https://orcid.org/0000-0001-9278-7012 \\ Federal Institute of Goias, Brazil \\ E-mail: kelycaiado@gmail.com
}

\section{Resumo}

Nos últimos anos a adsorção utilizando materiais alternativos como plantas orgânicas e materiais residuais tem sido utilizada e tem recebido muita atenção dos pesquisadores sobre o assunto. Neste trabalho, estudamos o processo de adsorção usando serragem de angelim, casca de arroz e MDF. O objetivo deste trabalho é selecionar o melhor material para a adsorção de água residuária contendo corantes através do método AHP (Analytic Hierarchy Process). Neste método foi realizada uma comparação entre os métodos dos pesos relativos e dos pesos aplicado aos métodos da soma dos pesos e do produto dos pesos. O material de seleção neste estudo foi feito para efluente contendo corante em solução e quatro fatores, absortividade (ABS), concentração do corante adsorvido (NAS), turbidez (TUR), tempo de adsorção (TAS).

Palavras-chave: Multicritérios. Processo de análise hierárquica. Peso relativo. Peso.

\begin{abstract}
In recently years the adsorption using alternatives materials such as organic plants and remains materials has been used and has had a lot of attention of the researchers on the subject. In this work, we have studied the adsorption process using angelim sawdust, rice husk and MDF. The objective of this work is to select the best material for adsorption of wastewater containing dyes using the AHP (Analytic Hierarchy Process) method. In this method, a comparison was made between the methods of relative weights and weights applied to the methods of the sum of weights and the product of the weights. The selection material in this study was made for wastewater contend dye in solution and four factors, absorptivity (ABS), concentration of adsorbed dye (NAS), turbidity (TUR), time of adsorption (TAS).
\end{abstract}

Keywords: Multi criteria. Analytical hierarchy process. Relative weight. Weight. 


\section{Nomenclature}

a performance value of the i-th alternative.

$\mathrm{a}_{\mathrm{ij}}$ actual value.

Am matrix of alternatives.

Awsm score of the best alternative.

CI consistency index.

$\mathrm{C}_{\mathrm{i}} \quad$ criterion.

$\mathrm{Cj}$ decision matrix.

CR consistency ratio .

$\mathrm{NC}$ number of criteria.

$\mathrm{P}$ preference.

RI is the random index.

RW Relative Weights.

W weights .

$\lambda$ eigenvectors.

$\lambda_{\max }$ maximum eigenvalue.

\section{Introduction}

In the field of the waste industrial effluents, the Physical-chemical treatment is widely used for removal impurities, heavy metals and others undesirable compounds present in the wastewaters. One of the physical-chemical processes used for this purpose is the adsorption. It can be applying in textile industries for removing dyes of wastewater.

According to Geankoplis (2010) adsorption is a unitary process that aims to remove one or more of the components that are present in a liquid or gas stream or solid on the surface of a solid adsorbent.

If we have several materials for this purpose, we are front of a dilemma, what is the best material? In some cases, what is the best material and the best condition for the adsorption process? To answer these questions, we use a powerful mathematical tool that is Multi Criteria Decision Analysis (MCDA) for helping in the design in the adsorption process.

According to Belton and Stewart (2002), Multi Criteria Decision Analysis "is a term that includes a set of concepts, methods and techniques that seek to help individuals or groups to make decisions, which involve several points of view in conflict and multiple stakeholders.

We can use several decision-making models however, to verify which of the models is most appropriate is not a trivial task. This work is proposed a technique known as Multi Criteria Decision Analysis (MCDA) using the AHP (Analytic Hierarchy Process) (Aragonés-Beltrán et al., 2009).

\section{Reviews of Adsorption}

Adsorption is a unitary operation involving physical, chemical and biological systems and is present in a wide variety of industrial applications. Adsorption is related to the property of some solids removing undesirable substances present in a liquid phase or in the gaseous phase, for example the removal of dyes presents in a liquid phase. The ability of some solids to remove dyes is a secular property known for the observation of natural phenomena, but the physical and thermodynamic reasons involved in these phenomena were not known before the advent of the twentieth century. Following are some of the pioneering sources of understanding of the phenomenon of adsorption: 
- $\quad$ Liu and Zhang (2007) used natural and modified clays. This modification was made through acidification, calcination and treatment with organic molecules and the materials were effective in adsorption of many dyes (e.g., 3D rhodamine, methyl green, methylene blue, basic blue 9, basic red 18, basic yellow 57, basic brown 16, victoria blue, congo red, direct orange, etc.) of aqueous solutions.

- Bhattacharyya and Gupta (2008) used kaolanita and its modified forms in the removal of As (III)/As(V), Cd(II), Cr(III)/VI), Co(II), Cu(II), Fe(III), Pb(II), Mn(II), Ni(II), Zn(II), etc., under various physicochemical conditions of $\mathrm{pH}$, temperature, adsorbent quantity and adsorbate concentration

- Wang and Peng (2010) used modified zeolites through acids and base or surfactant treatments for the treatment of wastewater contaminated with ammonium, heavy metals and dyes.

\section{Goal of this work}

In this work it was proposed the use of three adsorbent materials of the unconventional type angelim sawdust, rice husk and MDF. These subjects were chosen due to their ease of acquisition in the metropolitan region of Goiânia-Brazil. These materials were chosen for the treatment of wastewater containing dyes.

As explained above, the parameters of adsorption isotherms are obtained by means of a laboratory experiment. These experiments are usually long and can be costly and spend too much time to get the results. Many of these experiments are done by testing more than one adsorbent component. From these experiments, the isotherm data must be collected for each type of material. To minimize these steps, this work shows that a study can be made, based on optimization methods to select the most suitable material for the adsorption process. If we do this preliminary analysis we can eliminate many experimental steps and thus do the experimental analyzes only for those materials more indicated for adsorption instead of all of them.

The method used here is based on the criteria that are important in the selection of a particular adsorbent. From these criteria an analysis is made between them until an outcome is obtained showing the decreasing sequence of the best material for the less indicated material.

\section{Methodology}

In this work the method used to select the most appropriate adsorption material of wastewater dyes will be that of the Multi Criteria Decision Analysis applied to the Analytical Hierarchy Process. The parameters used as criteria in the selection of the most appropriate adsorbent were absorbed (ABS), design of adsorbed dye (NAS), turbidity (TUR) and adsorption time (TAS)

\section{Evaluation Process}

In this work, the decision-making process proposed consist of the following steps, Figure 1. 


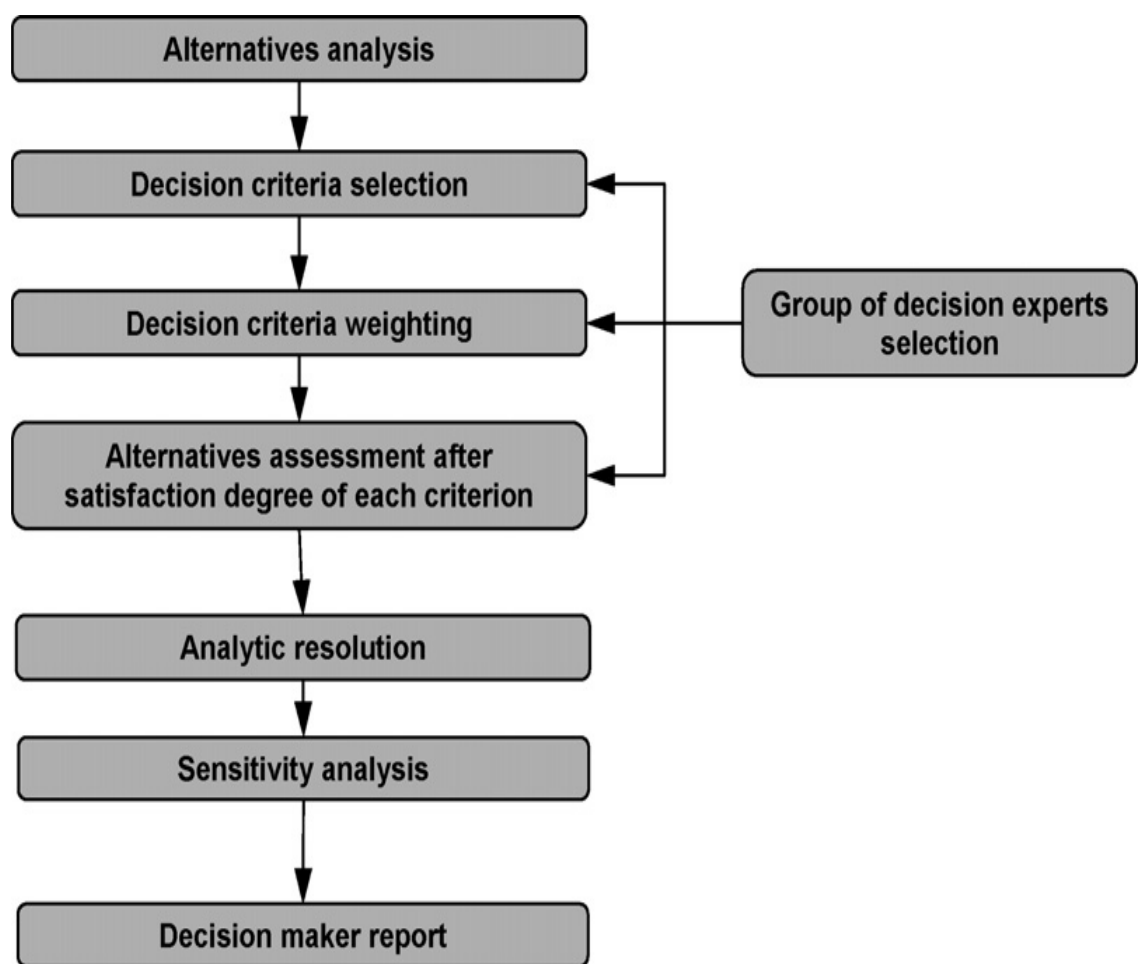

Figure 1 - Decision-Making Process (Aragonés-Beltrán, et al., 2009)

The chemical physical properties of the solution to be treated by the adsorbent should be obtained in such a way that the decision process is as reliable as possible.

\section{Best material selection with MCDA: the AHP method}

\subsection{The AHP method}

The decision-making process usually is not so easy and several times complex. Saaty, (2005) was one of the first to develop the AHP method which is an already well-established method and is used in multi-criteria-based decision-making processes

When we have o lot of objectives to be reached, the multicriteria decision analysis helps us to find the best solution and the process contains the following steps Saaty (2005):

1. Define the alternatives.

2. Define the most important criteria.

3. Evaluate the alternatives against the criteria.

4. Asses the relative importance of each criterion.

5. Determine the overall assessment of each alternative.

As we know, is complex to solve problems where are involved multiples criteria and alternatives. Therefore, the AHP method was developed to solve this problem through the construction of hierarchic structures that contains the goal, alternatives and criteria.

Thus, the AHP method was developed to solve this problem by constructing hierarchical structures that contain the objective, alternatives and criterias. Alternatives should be evaluated based on the decision criteria and their relative importance, also weight-less and each criterion are also estimated. Be aij with $\mathrm{i}=(1,2, \mathrm{M}$, and $\mathrm{N}=1,2, \mathrm{M})$ that indicates the performance value of the alternative $\mathrm{i}$-th $(\mathrm{Ai})$ in relation to the terms of $\mathrm{j}$-th $(\mathrm{Cj})$ criteria. The $\mathrm{Cj}$ criterion comes with wj weight. Once these parameters have been carefully chosen, the Decision Matrix is constructed as shown in Table 1. This table is a typical MCDM problem (Triantaphyllou et al, 1995): 
Table 1 - Decision Matrix.

\begin{tabular}{cllll}
\hline & \multicolumn{5}{c}{ Criterion } \\
\hline & $\mathrm{C}_{1}$ & $\mathrm{C}_{2}$ & $\ldots$ & $\mathrm{C}_{\mathrm{N}}$ \\
\hline & & \multicolumn{3}{c}{ weights } \\
\hline Alternatives & $\mathrm{w}_{1}$ & $\mathrm{w}_{2}$ & $\ldots$ & $\mathrm{w}_{\mathrm{j}}$ \\
$\mathrm{A}_{1}$ & $\mathrm{a}_{11}$ & $\mathrm{a}_{12}$ & $\ldots$ & $\mathrm{a}_{1 \mathrm{~N}}$ \\
$\mathrm{~A}_{2}$ & $\mathrm{a}_{21}$ & $\mathrm{a}_{22}$ & $\ldots$ & $\mathrm{a}_{2 \mathrm{~N}}$ \\
$\cdot$ & $\cdot$ & $\cdot$ & $\ldots$ & $\ldots$ \\
$\cdot$ & $\cdot$ & $\cdot$ & $\ldots$ & $\ldots$ \\
$\cdot$ & $\cdot$ & $\cdot$ & $\ldots$ & $\ldots$ \\
$\mathrm{A}_{\mathrm{M}}$ & $\mathrm{a}_{\mathrm{M} 1}$ & $\mathrm{a}_{\mathrm{M} 2}$ & $\ldots$ & $\mathrm{a}_{\mathrm{MN}}$ \\
\hline
\end{tabular}

In this matrix, should calculate the eigenvectors using the software MATLAB R2018 implemented on Lenovo intel computer ${ }^{\circledR}$ Core ${ }^{\mathrm{TM}}$ i7-7500 CPU.

[autovet autoval] $=\operatorname{eing}(\mathrm{A})$

Where:

autovet are eigenvectors

autoval are eigenvalues

$\mathrm{A}$ is the decision matrix

After this, we are ready to calculate the weights of the matrix. Once we calculate the eigenvectors, the weights are obtained by normalizing the eigenvector as shown below:

$$
w_{j}=\frac{\lambda_{j}}{\sum \lambda_{j}}
$$

$\mathrm{w}_{\mathrm{j}}$ are the weights.

$\lambda_{\mathrm{j}}$ is the eigenvectors.

$\operatorname{sum}\left(\lambda_{\mathrm{j}}\right)$ is the sum of all eigenvectors.

The elements of the decision matrix are obtained through a judgment of the criteria. These judgments of the criteria are defined from the absolute scale of the AHP that has an interval from 1 to 9. Each numerical value in Table 2 represents intensity of the criterion classified according to its intensity of interference in the decision-making process.

Table 2 - Relative Importance Measurement Scale

\begin{tabular}{cc}
\hline Importance intensity & Definition \\
\hline 1 & Equal importance \\
3 & Weak importance \\
5 & Moderate importance \\
7 & Strong importance \\
9 & Extreme importance \\
$2,4,6,8$ & Intermediate values \\
\hline
\end{tabular}


The following rules must be obeyed to obtain each aij element from the decision matrix:

$$
a_{i j}>0 ; a_{i j}=1 / a_{i j} ; a_{i i}=1
$$

After we build the decision matrix, we are ready to select what is the best alternative of the process. For this purpose, we have two methods to resolve the problem:

\section{i. WSM (Weighted Sum Method)}

In MCDA, one of the most popular approach used is the WSM. Given the alternatives $\mathrm{M}$ and $\mathrm{N}$ criterias, the appropriate way to choose the best alternative is based on the expression of (Solnes J, 2003).

$$
A_{W S M}=\max \left[\sum_{i}^{j} a_{i j} w_{j}\right]
$$

In Equation 4, WSM represents the classification of the best alternative, $\mathrm{N}$ is the number of decision criteria, aij is the actual value of the $\mathrm{i}$-th alternative in terms of the $\mathrm{j}$-th criterion, and wj is the weight of the importance of the $\mathrm{j}$-th criteria. The sum of the products is equal to the total value of each alternative. This methodology presents a difficulty when it applies to multidimensional decision-making problems

\section{ii. WPM (Weighted Product Method)}

When we compared this method with the WSM, we can see that they are similar each other. The difference between them is that instead of addition, in the WPM, there is a multiplication. According to Pohekar and Ramachandran, each alternative is compared with the others by multiplying a number of ratios, one for each criterion. Each ratio is raised to the power equivalent to the relative weight of the corresponding criterion. In general, to compare the alternatives $A_{K}$ and $A_{L}$ the following product is obtain (Solnes, 2003):

$$
R\left(A_{K} / A_{L}\right)=\sum_{j=1}^{N}\left({ }^{a_{K j}} / a_{L j}\right)^{w_{j}}
$$

$\mathrm{N}$ is the number of criteria, aij is the actual value of the alternative $\mathrm{i}$-th in terms of criterion $\mathrm{j}$-th and wj is the weight of the importance of the criterion $j$-th. If $R$ (AK/AL) is greater than one, then the alternative $\mathrm{AK}$ has preference over the AL alternative (in the case of maximization). The best alternative is that saddle is at least identical in relation to other alternatives (Gal and Hanne, 1999).

In this work, the two methodologies described above will be used to select the best material for the adsorption of dye wastewater. For this problem, Figure 2 shows a schema containing three criteria and three alternatives. 


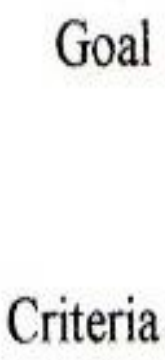

\section{Alternatives}

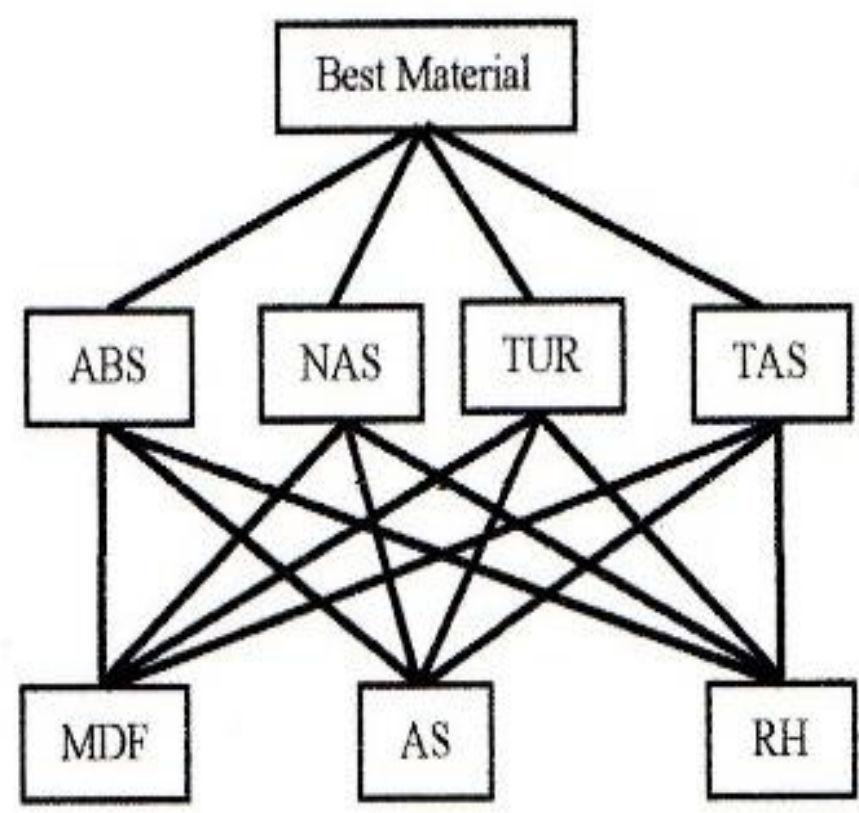

Figure 2 - A hierarchal tree representation of the problem with three alternatives and three criteria.

After the decision matrix, Table 1, was built, an important question arises. How do I know if the judgments are correct? Better, how do I know if the judgments are consistent? To determinate if the judgments are consistent we can calculate the consistency ratio (CR), defined as (Deb, K., 2001)

$$
C R=\frac{C I}{R I}
$$

Where $\mathrm{CI}$ is the consistency index and RI is the random index. $\mathrm{CI}$ is defined as:

$$
C I=\frac{\lambda_{\max -n}}{n-1}
$$

Where $\lambda_{\max }$ is the maximum eigenvalue, this value can obtained by using MATLAB R2018, $\mathrm{n}$ is the matrix decision's dimension and RI as given in Table 3:

\section{Table 3 - RI values for different values of $\mathbf{n}$}

\begin{tabular}{lccccccccc}
\hline $\mathrm{n}$ & 1 & 2 & 3 & 4 & 5 & 6 & 7 & 8 & 9 \\
$\mathrm{RI}$ & 0 & 0 & 0.58 & 0.90 & 1.12 & 1.24 & 1.32 & 1.41 & 1.45 \\
\hline \multicolumn{7}{l}{} \\
\hline
\end{tabular}

According to Hajeeh, Al-Othman, (2005), If during the trial process the CR value of the matrix is high, this indicates that the judgments were inconsistent, therefore, are not reliable. A consistency ratio of up to 0.1 can be considerably acceptable. If the input number is greater than 1 , the criteria in this row are preferred over the value in this column; otherwise, the value of the column is preferred. 
Each criterion has a property called relative weight (RW). This property indicates the importance of each criterion, which informs to us the importance for each criterion in the process. The RW can be calculated using the following relationship: (Saaty, 2008).

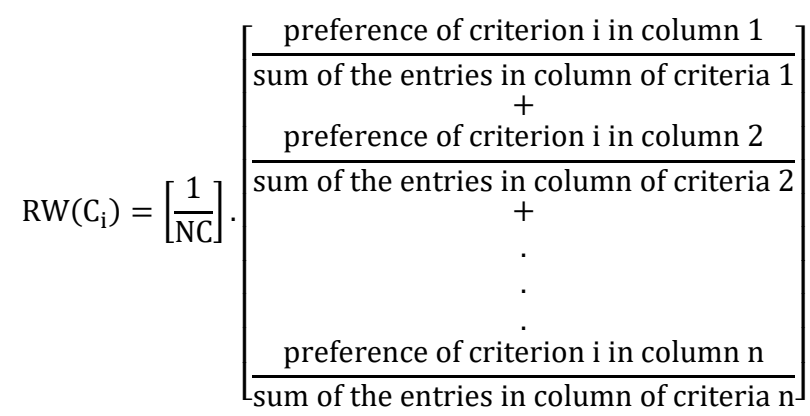

Where $\mathrm{NC}$ is the number of criteria, $\mathrm{C}_{\mathrm{i}}$ is criterion.

For this methodology, was to construct each preferences matrix for the results obtained from comparing different adsorption's materials. The matrices are represented in Tables 4-8.

\section{Results and discuss}

The relative weights and weights of each criteria were calculated as shown in the matrices in Tables 4-8. The Tables 5-8 represents the pair-wise comparison of the different materials under each criterion. These tables are represented also the relative weights and consistency ratio. The SWM and WPM methods were used to determine the ranking of selected materials for the adsorption of dyes. The tables 9 and 10 represents de decision matrix like table 1, where that methods were applied. All tables show that the CR values are smaller than 0.1, therefore, all the judgments are consistent.

For example, to calculate RW, Equation 8 for criteria ABS in the Table 4 (row 1), using the equation (16), we have:

$$
R W_{A B S}=\left(\frac{1}{4}\right)\left(\frac{1}{13}+\frac{1 / 7}{1.5095}+\frac{1}{14}+\frac{1 / 4}{6.4147}\right)=0.0705
$$

Similarly, for the all the other criteria in the all tables, the RWs values were calculated using the Equation (8) and, the values of W, were calculated using the Equation (2). Table 4 shows the comparative result of weight (W) and relative weight (RW) for all criteria. The relative deviations between weight and RW, taking W, as reference since the AHP method uses weight (W), are determined according to the following equation:

$$
\Delta(\%)=\left(\frac{|R W-W|}{W}\right) \cdot 100
$$


Table 4 - Pair-wise comparation of the different criteria and their relative weights.

\begin{tabular}{ccccccccc} 
& ABS & NAS & TUR & TA & RW & w & $\Delta /(\%)$ & \\
\hline ABS & 1 & $1 / 7$ & 1 & $1 / 4$ & 0.0705 & 0.0660 & 6.81 & $\lambda_{\max }=4.2526$ \\
NAS & 7 & 1 & 6 & 5 & 0.6022 & 0.6297 & 4.36 & $\mathrm{CI}=0.084$ \\
TU & 1 & $1 / 6$ & 1 & $1 / 6$ & 0.0712 & 0.0648 & 9.81 & $\mathrm{CR}=0.09$ \\
TA & 4 & $1 / 5$ & 6 & 1 & 0.2562 & 0.2395 & 6.97 & $\mathrm{RI}=0.90$ \\
sum & 13.0 & 1.5095 & 14.0 & 6.4147 & 1.0000 & 1.0000 & & \\
\hline
\end{tabular}

Table 5: Pair-wise comparison of the different material with respect to require absorvity (ABS). Relative weights (RW) and weights (w).

\begin{tabular}{cccccccc}
\hline ABS & MDF & AS & RH & RW & w & $\Delta(\%)$ & \\
\hline MDF & 1 & 2 & 5 & 0.5813 & 0.5815 & 0.034 & $\lambda_{\max }=3.0037$ \\
AS & $1 / 2$ & 1 & 3 & 0.3091 & 0.3090 & 0.032 & CI $=0.0018$ \\
RH & $1 / 5$ & $1 / 3$ & 1 & 0.1096 & 0.1095 & 0.091 & CR $=0.0032$ \\
sum & 1.7000 & 3.3333 & 9.000 & 1.0000 & 1.0000 & & RI $=0.58$ \\
\hline
\end{tabular}

Table 6 - Pair-wise comparison of the different material with respect to require concentration of adsorbed dye (NAS). Relative weights (RW) and weights (w).

\begin{tabular}{cccccccc}
\hline NAS & MDF & AS & RH & RW & w & $\Delta(\%)$ & \\
\hline MDF & 1 & 2 & 4 & 0.5572 & 0.5584 & 0.2295 & $\lambda_{\max }=3.0183$ \\
AS & $1 / 2$ & 1 & 3 & 0.3202 & 0.3196 & 0.1939 & CI $=0.0091$ \\
RH & $1 / 4$ & $1 / 3$ & 1 & 0.1226 & 0.1220 & 0.5427 & CR $=0.0158$ \\
sum & 1.7500 & 3.3333 & 8.000 & 1.0000 & 1.0000 & & RI $=0.58$ \\
\hline
\end{tabular}

Table 7 - Pair-wise comparison of the different material with respect to require turbidity (TUR). Relative weights (RW) and weights (w).

\begin{tabular}{lccccccc}
\hline TUR & MDF & AS & RH & RW & W & $\Delta(\%)$ & \\
\hline MDF & 1 & 3 & 5 & 0.6194 & 0.6267 & 1.1719 & $\lambda_{\max }=3.0858$ \\
AS & $1 / 3$ & 1 & 4 & 0.2842 & 0.2797 & 1.6236 & CI $=0.0429$ \\
RH & $1 / 5$ & $1 / 4$ & 1 & 0.0964 & 0.0936 & 2.9946 & CR $=0.0158$ \\
sum & 1.5333 & 4.25 & 10.000 & 1.0000 & 1.0000 & & RI $=0.58$ \\
\hline
\end{tabular}


Table 8 - Pair-wise comparison of the different material with respect to require adsorption time (TA). Relative weights (RW) and weights (w).

\begin{tabular}{cccccccc}
\hline TA & MDF & AS & RH & RW & W & $\Delta(\%)$ & \\
\hline MDF & 1 & 5 & 7 & 0.7235 & 0.7306 & 0.931 & $\lambda_{\max }=3.0649$ \\
AS & $1 / 5$ & 1 & 3 & 0.1932 & 0.1884 & 2.548 & CI $=0.0324$ \\
RH & $1 / 7$ & $1 / 3$ & 1 & 0.0833 & 0.0810 & 0.028 & CR $=0.0559$ \\
sum & 1.3429 & 6.3333 & 11.000 & 1.0000 & 1.0000 & & RI $=0.58$ \\
\hline
\end{tabular}

As the $\Delta$ results show us in the tables above, the percentage deviation between RW and W are small, which indicates that we use, to the WSM and WPM methods, one or the other RW and W. The ranking of the alternatives is determined using the WSM and WPM. For these methods, the matrices of different materials to respect to several criteria are the different materials to respect to several criteria are show in Table 9.

Table 12: Rank of the different materials according to the various criteria, using RW.

\begin{tabular}{lcccc}
\hline & $\mathrm{ABS}$ & $\mathrm{NAS}$ & $\mathrm{TUR}$ & $\mathrm{TA}$ \\
\hline & $\mathrm{RW}_{1}=0.0660$ & $\mathrm{RW}_{2}=0.6022$ & $\mathrm{RW}_{3}=0.0712$ & $\mathrm{RW}_{4}=0.2562$ \\
\hline $\mathrm{MDF}$ & 0.5816 & 0.5571 & 0.6267 & 0.7306 \\
$\mathrm{AS}$ & 0.3090 & 0.3202 & 0.2797 & 0.1884 \\
$\mathrm{RH}$ & 0.1095 & 0.1220 & 0.0936 & 0.0810 \\
\hline
\end{tabular}

According to WSM, Equation (4), the ranking sequence is:

$\mathrm{A}_{\mathrm{MDF}}=0.6059 ; \mathrm{A}_{\mathrm{AS}}=0.2844 ; \mathrm{A}_{\mathrm{RH}}=0.1098$

Therefore: MDF > AS > RH

According to WPM, equation (13), we have the following matrix:

\begin{tabular}{lll}
\hline 1.0000 & 2.1636 & 5.5595 \\
0.4622 & 1.0000 & 2.5696 \\
0.1799 & 0.3892 & 1.0000 \\
\hline
\end{tabular}

The most important elements of the matrix above are those larger then 1, so:

$\mathrm{MDF} / \mathrm{AS}=2.1636: \mathrm{MDF} \boldsymbol{P}$ AS

$\mathrm{MDF} / \mathrm{RH}=5.5595: \mathrm{MDF} \boldsymbol{P} \mathrm{RH}$

$\mathrm{AS} / \mathrm{RH}=2.5696:$ AS $\boldsymbol{P}$ RH.

Then, the ranking sequence is: $\mathrm{MDF}>\mathrm{AS}>\mathrm{RH}$ 
Table 13: Rank of the different materials according to the various criteria, using $w$.

\begin{tabular}{lcccc} 
& ABS & NAS & TU & TA \\
\hline & $\mathrm{w}_{1}=0.0705$ & $\mathrm{w}_{2}=0.6022$ & $\mathrm{w}_{3}=0.0712$ & $\mathrm{w}_{4}=0.2562$ \\
\hline MDF & 0.5813 & 0.5584 & 0.6194 & 0.7235 \\
AS & 0.3092 & 0.3196 & 0.2842 & 0.1932 \\
RH & 0.1096 & 0.1226 & 0.0964 & 0.0810 \\
\hline
\end{tabular}

According to WSM, Equation (4), the ranking sequence is:

$\mathrm{A}_{\mathrm{MDF}}=0.6067 ; \mathrm{A}_{\mathrm{AS}}=0.2840 ; \mathrm{A}_{\mathrm{RH}}=0.1092$

Therefore: MDF > AS > RH

According to WPM, equation (13), we have the following matrix:

\begin{tabular}{lll}
\hline 1.0000 & 2.1690 & 5.6074 \\
0.4610 & 1.0000 & 2.5852 \\
0.1783 & 0.3868 & 1.0000 \\
\hline
\end{tabular}

The most important elements of the matrix above are those larger then 1, so:

$\mathrm{MDF} / \mathrm{AS}=2.1690: \mathrm{MDF} \mathbf{P}$ AS

$\mathrm{MDF} / \mathrm{RH}=5.6074: \mathrm{MDF} \mathbf{P} \mathrm{RH}$

$\mathrm{AS} / \mathrm{RH}=2.5852:$ AS P RH.

Then, the ranking sequence is:

$\mathrm{MDF}>\mathrm{AS}>\mathrm{RH}$

\section{Conclusion}

This study investigated adsorption technology process. Our study showed that the AHP method was applied successfully. The methods of WSM and WPM showed that the material more suitable for dye adsorption of wastewater is MDF. Our study also showed that we can use RW and w for WSM and WPM methods, once the $\Delta$ values were small. We suggest for future study to apply other techniques multicriteria decision.

\section{Acknowledgements}

We are thankful for assistance from the Elaine Alves Faria Braga. 


\section{References}

Aragonés-Beltran, P., García-Melon, M., Montesinos-Valera (2017). How to assess stake holder's influence in project management? A proposal based on the analytic Network Process. 35(3), p 451-462. https://doi.org/10.1016/j.ijproman.2017.01.001

Babel, S., Kurniawan, T.A. (2003). Low-Cost Adsorbents for Heavy Metal Uptake from Contaminated Water: A Review. J Hazarsdous Mater. 97, 219-243. https://doi.org/10.1016/S0304-3894(02)00263-7

Babel, S., Kurniawan, T.A. (2004). Cr(VI) Removal from Synthetic Wastewater Using Coconut Shell Charcoal and Commercial Activated Carbon Modified with Oxidizing Agents And/or Chitosan. Chemosphere. 54(7), 951-967. https://doi.org/10.1016/j.chemosphere.2003.10.001

Belton, V., Stewart, T. (2002) Multiple Criteria Decision Analysis. An Integrated Approach, Kluwer Academic Publishers.

Bouyssou, D., Marchant, T., Pirlot, M., Perny, P., Tsoukias A., Vincke P. (2002). Evaluation and Decision Models. A Critical Perspective. Kluwer Academic Publishers.

Barry, C.N, W John, W. T. (1998). Adsorption Technology and Design. Lymington: ButterworthHeinemann.

Bhatnagar, A., Sillanpää, M. (2010). Utilization of Agro-Industrial and Municipal Waste Materials as Potential Adsorbents for Water Treatment-A review. Chemical Engineering Journal, Hamburg, 157(2-3), 277-296. https://doi.org/10.1016/j.cej.2010.01.007

Bhattacharyya, K. G., Sharma, A. (2004). Azadirachta Indica Leaf Powder as An Effective Biosorbent For Dyes: A Case Study with Aqueous Congo Red Solutions. Journal of Environmental Management, 71(3), 217-229. https://doi.org/10.1016/j.jenvman.2004.03.002

Bhattacharyya, K. G.; Gupta, S. S. (2008). Adsorption of a Few Heavy Metals on Natural and Modified Kaolinite and Montmorillonite: A review. Advances in Colloid and Interface Science. 140(2), 114-131. https://doi.org/10.1016/j.cis.2007.12.008

Bilba, D., Bilba, N., Moroi, G. (2007). Removal of Mercury (II) Ions from Aqueous Solutions by The Polyacrylamidoxime Chelating Fiber. Separation Science and Technology,.42(1),171184. https://doi.org/10.1080/01496390600997922

Chang, Y.H, Yeh, C.H. (2001). Evaluating Airline Competitiveness Using Multi-Attribute Decision-Making. Omega 29(5), 405-15. https://doi.org/10.1016/S0305-0483(01)00032-9

Crittenden J.C., Reddy, P.S., Arora H., Trynoski J., Hand, D.W., Perram D.L., \& Summers R.S. (1991) Predicting GAC Performance with Rapid Small-Scale Column Tests. Journal American Water Works Association, 83(1), 77-87. https://doi.org/10.1002/j.15518833.1991.tb07088.x

Deb, K. Multi-Objective Optimization Using Evolutionary Algorithms. John Wiley \& Sons, Inc., New York, NY, USA, 2001.

Gal T, H. T. (1999). Multicriteria decision-making: Advances in MCDM models, algorithms, theory, and applications. New York: Kluwer Academic Publishers; 1999.

Geankoplis, C. J. (2010). Transport process principles. Prentice-Hall.

Hajee, M., Al-Othman, M. (2005). Application of the analytical hierarchy process in the selection of desalination plants. Elsivier. pp97-108. https://doi.org/10.1016/j.desal.2004.09.005

Hyde, K.M; Maier, H.R., \& Colby, C.B. (2005). A distance-based uncertainty analysis approach to multi-criteria decision analysis for water resource decision making. Journal of Environmental Management, 77 (4), 278-290. https://doi.org/10.1016/j.jenvman.2005.06.011

Liu, P., Zhang, L. (2007). Adsorption of dyes from aqueos solutions or suspensions with clay nanoadsorbents. 83 (1), 32-39. https://doi.org/10.1016/j.seppur.2007.07.007

Marler, R. T., Arora, J.S. (2010). The weighted sum method for multi-objective optimization: new insights. 41(6), 853 -862. https://doi.org/ 10.1007/s00158-009-0460-7 
Meyer, P., Olteanu, A.L. (2013). Formalizing and solving the problem of clustering in MCDA. European Journal of Operational Research. 227(3),494-502. https://doi.org/10.1016/j.ejor.2013.01.016

Miettinen, K. K. (1999). Nonlinear Multiobjective Optimization. Academic Publishers.

Pohekar, S.D., Ramachandran, M. (2004). Application of multi-criteria decision making to sustainable energy planning. A review. Elsevier. 365-381. https://doi.org/10.1016/j.rser.2003.12.007

Pomerol, J.C., Barba-Romero, S. (2000) Multicriterion Decision in Management: Principles and Practice. Kluwer Academic Publishers, Boston, 2000, Hardbound.

Saaty, T.L. (2008). Decision making with the analytic hierarchy process. Int. J. Services Sciences, $1(1)$.

Smyth, B. M.; Smyth, H., Murphy, J. D. (2001). Determing the regional potential for a grass biomethane industry. Applied Energy, 2011, 88 (6), 2037-2049. https://doi.org/10.1016/j.apenergy.2010.12.069

Solnes, J. (2003). Environmental quality indexing of large industrial development alternatives using AHP. Environmental Impact Assessment Review. Elsevier. 23(3), 283-303. https://doi.org/10.1016/S0195-9255(03)00004-0

Thomas, J.W., Crittend, B. (1998). Adsorption, Technology and Design. Butterworth-Heinemann

Triantaphyllou, E; Stuart H. Mann, S. H. (1995) Using the Analytic Hierarchy Process for Decision Making in Engineering Applications: Some Challenges. Inter'l Journal of Industrial Engineering: Applications and Practice. 2(1), 35-44.

Wang, S., Peng, Y. (2010) Natural zeolites as effective adsorbents in water and wastewater treatment. Chemical Engineering Journal. 56(1), 11-24. https://doi.org/10.1016/j.cej.2009.10.029

Wang, J.J; Jing, Y.Y; Zhao, J.H. (2009) Review on multi-criteria decision analysis aid in sustainable energy decision-making. Renewable and sustainable energy reviews.2009. 13(9), 2263-2278. https://doi.org/10.1016/j.rser.2009.06.021

Zhou, P.; Li-Wei, F.; De-Qun., Z. (2010). Data Aggregation in constructing composite indicators: A perspective of information loss. Expert Systems with Applications., 37(1), 360-365. https://doi.org/10.1016/j.eswa.2009.05.039 